\title{
Analisis Kualitas Pelayanan Bus Kota Surabaya Berdasarkan Persepsi Pengguna Dengan Metode Importance Performance Analysis (IPA)
}

\author{
Purwo Mahardi $^{1}$, Tri Sudibyo ${ }^{2}$, Fitri Rohmah Widayanti ${ }^{1}$ \\ ${ }^{1}$ Jurusan Teknik Sipil, Fakultas Teknik, Universitas Negeri Surabaya \\ ${ }^{2}$ Departemen Teknik Sipil dan Lingkungan, Institut Pertanian Bogor \\ Email : purwomahardi@unesa.ac.id
}

\begin{abstract}
Abstrak
Penelitian ini bertujuan untuk menganalisis tingkat harapan serta tingkat kinerja pelayanan bus kota di Surabaya menurut penumpang bus kota. Berkaitan dengan upaya peningkatan kualitas pelayanan, penelitian ini juga menganalisis faktor yang harus diprioritaskan, faktor yang harus dipertahankan, faktor dengan prioritas rendah dan faktor yang berlebihan. Indikator pelayanan sebanyak 13 variabel yang dikembangkan dari dimensi SERVQUAL. Metode analisis yang digunakan adalah Importance Performance Analysis (IPA) dengan jumlah responden sebanyak 120 penumpang yang diambil dari 6 trayek yang saat ini beroperasi. Hasil analisis gap menunjukkan bahwa tidak ada satupun indikator yang memenuhi harapan penumpang. Penumpang berasumsi bahwa kualitas pelayanan bus kota di Surabaya berada pada level cukup memuaskan. Faktor ketersediaan AC (Air Conditioner) merupakan faktor yang dianggap penting oleh pelanggan tetapi pada kenyataannya faktor ini masih jauh dari harapan. Faktor inilah yang harus mendapatkan prioritas utama dari operator untuk dibenahi agar kualitas pelayanan dapat meningkat sesuai harapan penumpang.
\end{abstract}

Kata kunci: importance performance analysis (IPA), pelayanan, tingkat kepuasan.

\begin{abstract}
This study aims to analyze the level of expectations and the level of performance of city bus services in Surabaya according to city bus passengers. In connection with efforts to improve the quality of service, this study also analyzes the factors that must be prioritized, factors that must be maintained, factors with low priority and excessive factors. Service indicators for 13 variables developed from SERVQUAL dimensions. The analytical method used is the Importance Performance Analysis (IPA) with a total of 120 passengers taken from 6 routes currently operating. The results of the gap analysis show that there are no indicators that meet passenger expectations. Passengers assume that the quality of city bus services in Surabaya is at a satisfactory level. The availability factor of AC (Air Conditioner) is a factor that is considered important by the customer but in reality, this factor is still far from expectations. This factor must get the top priority from the operator to be addressed so that service quality can increase according to passenger expectations.
\end{abstract}

Keywords: importance performance analysis (IPA), service, level of satisfaction.

\section{PENDAHULUAN}

Kebergantungan kota-kota besar di negara berkembang atas sistem transportasi berbasis jalan raya masih relatif tinggi. Dalam perkembangannya, kendaraan pribadi cenderung mendominasi dari segi jumlah dan preferensi penggunaan dibandingkan dengan angkutan umum. Dampak langsung yang terjadi dari meningkatnya populasi kendaraan pribadi adalah kemacetan jalan yang dapat diamati dari penurunan nilai kinerja pelayanan jalan (loss) sekalipun standar penilaian kinerja pelayanan jalan yang ada di Indonesia masih belum dapat memberikan nilai loss yang sama (Sudibyo dkk, 2017). Lebih spesifik lagi, Schipper dkk (2000) mengemukakan bahwa buruknya pelayanan angkutan umum khususnya bus kota mengakibatkan masyarakat cenderung memilih menggunakan kendaraan pribadi dan menimbulkan dampak lanjutan terkait dengan meningkatnya konsumsi bahan bakar, isu polusi lingkungan, dan isu social. Selain itu juga ada dampak terkait dengan waktu perjalanan dan isu keselamatan pengendara (Tolba dan Saab, 2008). 
Surabaya, kota terbesar kedua di Indonesia, menghadapi peliknya masalah sistem angkutan umum perkotaan. Bus kota tidak lagi menjadi pilihan transportasi masyarakat. Penurunan permintaan bus kota dapat dilihat dari banyaknya trayek yang dilayani, dari semula 14 trayek resmi hanya 6 trayek saja yang masih beroperasi. Pihak operator berpendapat bahwa biaya operasional kendaraan tidak sebanding dengan pendapatan yang diperoleh sehingga mereka terpaksa berhenti beroperasi di trayek tersebut. Dari keenam trayek tersebut, hanya satu trayek yang memiliki tingkat isian (load factor) yang dikategorikan layak yakni trayek Purabaya Jembatan Merah Plaza (JMP) dengan load factor sebesar $79.24 \%$. Rata-rata load factor untuk trayek yang lain hanya sebesar $39.506 \%$, jauh dari standar pemerintah $(70 \%)$.

Aminah (2007) dan Sugianto (2013) menyatakan bahwa rendahnya tingkat pelayanan operator angkutan umum berimbas pada penurunan minat masyarakat walaupun terdapat faktor lain yang juga mempengaruhi rendahnya minat yakni aksesibilitas dan tingkat ketersediaan (Shen J, Li W, 2014), rendahnya harga beli kendaraan pribadi dan perubahan gaya hidup masyarakat (Basuki, 2008). Dengan demikian, peningkatan pelayanan sangat penting dilakukan demi perbaikan kualitas angkutan umum dan mengurangi masalah dalam sistem transportasi (Costa dkk, 1997).

Peningkatan kualitas pelayanan angkutan umum harus memperhatikan keinginan atau harapan pengguna agar semua kepentingan pengguna dapat terakomodasi dan pengukuran kinerja pelayanan dilakukan dalam berbagai aspek (Beirao dan Cabral, 2007). Aspek penilaian kualitas pelayanan berkembang dari masa ke masa. Penelitian Parasuraman dkk (1985) terhadap pengguna dan operator mengindikasikan ada 2 (dua) aspek penting yang perlu diukur yakni jaminan (assurance) dan empati (emphaty). Jaminan (assurance) meliputi komunikasi, kompetensi, kesopanan, kredibilitas dan keamanan, sedangkan empati mencakup akses dan rasa pengertian.

Dalam perkembangannya, Parasuraman dkk (1991) mengusulkan 5 dimensi yang dapat digunakan untuk mengukur kualitas pelayanan yakni bukti fisik (tangibles), kehandalan (reliability), daya tanggap (responsiveness), jaminan (assurance), dan empati (emphaty) dan dikembangkan menjadi instrument pengukuran kualitas pelayanan yang dikenal dengan SERVQUAL (Service Quality).

Dalam perkembangannya, Carman (1990) mengusulkan agar tingkat kepentingan juga diukur selain mengukur tingkat kepuasan. Atas dasar pemikiran tersebut, metode Importance Performance Analysis (IPA) lebih tepat digunakan agar tingkat kepuasan dan kepentingan dapat diukur secara komprehensif serta dapat ditentukan variable yang perlu diprioritaskan (Martilla dan James 1977; Wong dkk, 2009). Metode IPA telah banyak diterapkan untuk mengukur tingkat pelayanan pada banyak bidang, antara lain pariwisata dan biro perjalanan (Enright dkk, 2005; Fache, 2000; Go dkk, 1997), pemerintahan (Wong, dkk, 2011), pendidikan (Joseph dkk, 1997; Nale dkk, 2000), dan sektor lainnya (Blose dkk, 2005). Atas dasar itulah penulis tertarik menggunakan metode IPA untuk menganalisis kualitas pelayanan bus kota di Surabaya menurut persepsi pengguna.

\section{METODE}

\section{Pendekatan Penelitian}

Metode pendekatan yang digunakan dalam penelitian adalah pendekatan kuantitatif untuk mengetahui persepsi pengguna terhadap kualitas pelayanan bus kota di Surabaya

\section{Teknik Pengumpulan Data}

Peneliti mengumpulkan data melalui lembar observasi (kuesioner) yang dibagikan dan diisi oleh 120 penumpang dari 6 (enam) trayek bus kota yang beroperasi di Surabaya. Adapun trayek yang menjadi objek penelitian adalah Purabaya - Bratang, Purabaya - Perak, Purabaya - Terminal Oso Wilangun (TOW), Purabaya - Jayabaya, Purabaya Semut, dan Purabaya - Jembatan Merah Plaza (JMP).

Surveyor selalu mendampingi responden ketika proses pengisian kuisioner. Proses pendampingan sangat penting mengingat mayoritas responden adalah masyarakat umum yang belum familiar dengan survey di dalam angkutan umum.

Dalam pengambilan sampel, penulis menggunakan metode probabilitas (probability sampling) dengan teknik single random sampling. Kuisioner dikembangkan dari dimensi SERVQUAL yang terdiri dari 5 dimensi yakni keandalan (reliability), ketanggapan (responsiveness), jaminan (assurance), empati (empathy), dan berwujud (tangibles) dengan menggunakan kuesioner likert dengan skala ordinal (1-5) seperti tercantum dalam Tabel 1. 
Tabel 1. Skala likert dalam kuisioner

\begin{tabular}{lcl}
\hline Indikator & Nilai & \multicolumn{1}{c}{ Keterangan } \\
\hline \multirow{3}{*}{ Kinerja } & 1 & Tidak baik \\
& 2 & Kurang baik \\
& 3 & Cukup baik \\
& 4 & Baik \\
& 5 & Sangat baik \\
\hline \multirow{3}{*}{ Harapan } & 1 & Tidak penting \\
& 2 & $\begin{array}{l}\text { Kurang } \\
\text { penting }\end{array}$ \\
& 3 & Cukup penting \\
& 4 & Penting \\
& 5 & Sangat penting \\
\hline
\end{tabular}

Kelima dimensi SERVQUAL dijabarkan dalam 13 variabel dan dilakukan kodefikasi untuk memudahkan pengolahan data. Adapun variabel dan notasi dapat dilihat pada Tabel 2.

Tabel 2. Notasi variabel dimensi

\begin{tabular}{|c|c|c|}
\hline Dimensi & Variabel & Notasi \\
\hline \multirow[b]{2}{*}{ Keandalan } & Kapasitas bus kota & Reall \\
\hline & $\begin{array}{l}\text { Kerapian Awak Bus } \\
\text { Kota }\end{array}$ & Real2 \\
\hline \multirow{2}{*}{ Ketanggapan } & $\begin{array}{l}\text { Informasi Tarif Bus } \\
\text { Kota }\end{array}$ & Res1 \\
\hline & $\begin{array}{l}\text { Ketetapan Tarif Bus } \\
\text { Kota }\end{array}$ & Res2 \\
\hline \multirow{2}{*}{ Jaminan } & Jaminan Keamanan & Ass 1 \\
\hline & Jaminan Keselamatan & Ass 2 \\
\hline \multirow{2}{*}{ Empati } & $\begin{array}{l}\text { Kesigapan Awak bus } \\
\text { Kota }\end{array}$ & Emp1 \\
\hline & $\begin{array}{l}\text { Ketersediaan Layanan } \\
\text { Pengaduan }\end{array}$ & Emp2 \\
\hline \multirow{5}{*}{ Berwujud } & $\begin{array}{l}\text { Tempat Duduk yang } \\
\text { Nyaman }\end{array}$ & Tangib1 \\
\hline & $\begin{array}{l}\text { Ketersediaan Air } \\
\text { Conditioner (AC) }\end{array}$ & Tangib2 \\
\hline & Interior Bus & Tangib3 \\
\hline & $\begin{array}{l}\text { Tersedianya Fasilitas } \\
\text { Disabilitas }\end{array}$ & Tangib4 \\
\hline & $\begin{array}{l}\text { Kebersihan di Dalam } \\
\text { Bus Kota }\end{array}$ & Tangib5 \\
\hline
\end{tabular}

\section{Teknik Analisis Data}

Penelitian ini menggunakan 3 teknik analisis data yakni analisis gap, analisis tingkat kesesuaian dan analisis kuadran Importance Performance Analysis (IPA).

\section{Analisis Gap}

Supranto (2007) menjelaskan bahwa analisis gap dilakukan dengan menghitung selisih antara nilai rata-rata penilaian kinerja dengan rata-rata nilai indeks harapan. dari masing-masing indikator dalam dimensi. Ada tiga penilaian kualitas layanan berdasar pada perspektif pelanggan (Budiono, 2013), yaitu:

1) perceived service $=$ expected service (kualitas layanan positif)

2) perceived service $>$ expected service (kualitas layanan ideal)

3) perceived service < expected service (kualitas layanan negatif

\section{Analisis Tingkat Kesesuaian}

Setelah dilakukan analisis gap, selanjutnya dilakukan analisis tingkat kesesuaian antara nilai kinerja dan nilai harapan menurut pengguna dilakukan dengan Persamaan 1 berikut.

$T k i=\frac{X i}{Y i} \times 100 \%$

\section{Keterangan :}

Tki $=$ Tingkat kesesuaian responden.

$\mathrm{Xi}=$ Skor rata-rata penilaian kinerja responden.

$\mathrm{Yi}=$ Skor rata-rata penilaian harapan responden.

Steers (1993) dalam Budiono (2013) menyarankan skala tingkat kepuasan sebagai berikut:

1) $20 \%-40 \%:$ : Kepuasan rendah

2) $41 \%-79 \%$ : Kepuasan sedang/cukup

3) $80 \%-100 \%:$ Kepuasan tinggi

\section{Analisis Diagram IPA}

Setelah dilakukan pengukuran tingkat kesesuaian, langkah selanjutnya adalah membuat diagram posisi importance - performance yang merupakan suatu bangun yang dibagi menjadi 4 (empat) kuadran yang dibatasi oleh dua buah garis berpotongan tegak lurus pada titik-titik sesuai Persamaan 2 dan Persamaan 3.

$\overline{\bar{X}}=\frac{\sum_{i=1}^{n} \bar{X}_{i}}{k}$

$\overline{\bar{Y}}=\frac{\sum_{i=1}^{n} \bar{Y}_{i}}{k}$

Keterangan :

$\overline{\bar{X}}=$ Rata-rata dari rata-rata skor tingkat kinerja seluruh atribut.

$\overline{\bar{Y}}=$ Rata-rata dari rata-rata skor tingkat harapan seluruh atribut.

$\mathrm{Xi}=$ Skor rata-rata penilaian kinerja responden.

$\mathrm{Yi}=$ Skor rata-rata penilaian harapan responden.

$\mathrm{k}=$ Banyaknya atribut yang mempengaruhi kepuasan 
Nilai tingkat kinerja akan diisikan pada sumbu mendatar (X), sedangkan sumbu tegak (Y) akan diisi oleh skor tingkat harapan.

Martilla dan James (1977) menyatakan bahwa diagram IPA dibagi menjadi empat buah kuadran berdasarkan hasil pengukuran kinerja dan harapan. Definisi untuk masing-masing kuadran ditunjukkan oleh uraian berikut (Budiono, 2013):

1) Kuadran A, "Concentrate Here" (high importance \& low satisfaction)

Faktor-faktor yang terletak di kuadran satu dianggap sebagai faktor yang sangat penting dan menjadi prioritas oleh pengguna namun pada saat ini belum memuaskan sehingga pengelola berkewajib agar kinerja faktor tersebut dapat meningkat

2) Kuadran B, "Keep up The Good Work" (high importance \& high satisfaction).

Faktor-faktor yang terletak di kuadran dua dianggap sebagai faktor penunjang bagi kepuasan pengguna sehingga pengelola berkewajiban memastikan bahwa kinerja sistem yang dikelolanya dapat terus mempertahankan prestasi yang telah dicapai.

3) Kuadran C, "Low Priority" (low importance \& low satisfaction).

Faktor-faktor yang terletak di kuadran tiga mempunyai tingkat kepuasan yang rendah dan sekaligus dianggap tidak terlalu penting bagi pengguna, sehingga pengelola tidak perlu memprioritaskan faktor -faktor tersebut.

4) Kuadran D, "Possible Overkill" (low importance \& high satisfaction).

Faktor-faktor yang terletak di kuadran empat dianggap tidak terlalu penting sehingga pengelola perlu mengalokasikan sumber daya yang terkait dengan faktor- faktor tersebut kepada faktorfaktor lain yang mempunyai prioritas penanganan lebih tinggi.

Dari pembagian kuadran selanjutnya dapat dianalisis faktor-faktor yang selayaknya menjadi prioritas untuk dikembangkan agar kualitas pelayanan meningkat sesuai harapan pengguna.

\section{HASIL DAN PEMBAHASAN}

\section{Indeks Kualitas Pelayanan Bus Kota}

Perhitungan indeks kualitas pelayanan bus kota diperlukan sebelum melakukan analisis gap dan analisis tingkat kesesuaian. Hasil perhitungan indeks kualitas pelayanan dapat dilihat dalam Tabel 3.
Tabel 3. Indeks Kualitas Pelayanan Bus Kota

\begin{tabular}{cccc}
\hline \multirow{2}{*}{ Dimensi } & Indikator & Kinerja & Harapan \\
& & $\mathrm{X}$ & $\mathrm{Y}$ \\
\hline \multirow{2}{*}{ Keandalan } & Real1 & 3,59 & 3,99 \\
& Real2 & 3,29 & 3,77 \\
\hline \multirow{2}{*}{ Ketanggapan } & Res1 & 3,39 & 4,11 \\
& Res2 & 2,39 & 3,58 \\
\hline \multirow{2}{*}{ Jaminan } & Ass1 & 3,38 & 4,3 \\
& Ass2 & 3,25 & 4,28 \\
\hline \multirow{5}{*}{ Empati } & Emp1 & 3,58 & 3,96 \\
& Emp2 & 2,18 & 3,25 \\
\hline \multirow{6}{*}{ Berwujud } & Tangib 1 & 3,33 & 4,04 \\
& Tangib 2 & 2,99 & 3,97 \\
& Tangib3 & 3,09 & 3,66 \\
& Tangib4 & 2,08 & 3,64 \\
& Tangib5 & 3,18 & 4,17 \\
\hline \multirow{2}{*}{ Rata-rata } & 3,06 & 3,90 \\
& & Xi & Yi \\
\hline
\end{tabular}

Berdasarkan Tabel 3 dapat diamati bahwa rata-rata indeks kinerja kualitas pelayanan bus kota yang dipersepsikan oleh penumpang adalah sebesar 3.06 sementara indeks kualitas pelayanan bus kota yang diharapkan sebesar 3.90.

\section{Analisis Gap}

Setelah dilakukan perhitungan indeks kualitas pelayanan, selanjutnya akan dihitung kesenjangan (gap) antara kinerja dan harapan sesuai dengan persepsi penumpang. Hasil perhitungan gap untuk masing-masing indicator dari kelima dimensi SERVQUAL dapat dilihat pada Tabel 4.

Tabel 4. Analisis Gap Indikator Pelayanan

\begin{tabular}{lcc}
\hline \multicolumn{1}{c}{ Indikator } & Notasi & Gap \\
\hline Kapasitas bus kota & Real1 & $-0,40$ \\
Kerapian Awak Bus Kota & Real2 & $-0,48$ \\
\hline Informasi Tarif Bus Kota & Res1 & $-0,72$ \\
Ketetapan Tarif Bus Kota & Res2 & $\mathbf{- 1 , 1 9}$ \\
\hline Jaminan Keamanan & Ass1 & $\mathbf{- 0 , 9 2}$ \\
Jaminan Keselamatan & Ass2 & $\mathbf{- 1 , 0 3}$ \\
\hline Kesigapan Awak bus Kota & Emp1 & $-0,38$ \\
Ketersediaan Layanan Pengaduan & Emp2 & $\mathbf{- 1 , 0 7}$ \\
\hline Tempat Duduk yang Nyaman & Tangib 1 & $-0,71$ \\
Ketersediaan Air Conditioner (AC) & Tangib 2 & $\mathbf{- 0 , 9 8}$ \\
Interior Bus & Tangib3 & $-0,57$ \\
Tersedianya Fasilitas Disabilitas & Tangib4 & $\mathbf{- 1 , 5 6}$ \\
Kebersihan di Dalam Bus Kota & Tangib5 & $\mathbf{- 0 , 9 9}$ \\
\hline \multicolumn{1}{c}{ Rata-rata } & & $-0,85$ \\
\hline
\end{tabular}


Gap yang bernilai negatif menunjukkan bahwa kinerja kualitas pelayanan bus kota belum sesuai dengan tingkat harapan penumpang. Dari beberapa indikator pelayanan, setidaknya ada 7 indikator dengan selisih gap yang besar $(>0.85)$. Indikator tersebut antara lain:

1) Responsiveness-2 (Ketetapan Tarif Bus)

Kesenjangan pada indikator ini menunjukkan adanya ketidaksesuaian antara tarif yang sudah ditetapkan oleh pemerintah dengan tarif yang dipungut ketika bus beroperasi. Tarif di lapangan acapkali lebih besar daripada tarif resmi. Operator beralasan bahwa kenaikan tarif tersebut dilakukan untuk menutup biaya operasional kendaraan.

2) Assurance-1 (Jaminan Keamanan di Dalam Bus Kota)

Penumpang merasa keamanan mereka selama perjalanan tidak terlalu terjamin karena tidak adanya petugas khusus yang bertugas mengawasi keamanan penumpang. Selain itu ada kesan bahwa operator tidak terlalu peduli dengan keamanan penumpang dan menyerahkan semua tanggung jawab kepada masing-masing penumpang.

3) Assurance-2 (Jaminan Keselamatan di Dalam Bus Kota)

Faktor yang membuat adanya kesenjangan yang cukup tinggi pada indikator ini adalah tidak semua bus kota dilengkapi dengan fasilitas keselamatan seperti Alat Pemadam Api Ringan (APAR), kotak piranti Pertolongan Pertama Pada Kecelakaan (P3K), maupun palu pemecah kaca.

4) Empathy-2 (Ketersediaan Layanan Pengaduan)

Perhubungan dan Lalu Lintas Angkutan Jalan (Dishub dan LLAJ) Provinsi Jawa Timur pada tahun 2010 mencanangkan program penempelan stiker layanan pengaduan di semua bus kota namun seiring berjalannya waktu, stiker tersebut tidak lagi dapat dibaca dengan baik. Berbagai sarana pengaduan baik secara offline (di terminal) maupun online (aplikasi) juga tersedia, namun kurangnya sosialisasi membuat tidak banyak penumpang mengetahui hal tersebut dan berimbas pada penilaian mereka pada indikator ini menjadi kurang.

5) Tangible-2 (Ketersediaan Air Conditioner)

Suhu harian kota Surabaya yang relatif tinggi membuat ketersediaan AC menjadi faktor yang harus dipertimbangkan. Sebagian besar bus kota memiliki fasilitas tersebut namun kondisi dan performanya jauh dari harapan dikarenakan faktor usia. Semakin sedikitnya jumlah penumpang berpengaruh pada pendapatan operator yang juga berimbas pada berkurangnya alokasi biaya untuk perawatan AC.

6) Tangible-4 (Tersedianya Fasilitas Untuk Penumpang Disabilitas)
Secara garis besar, bus kota di Surabaya memang tidak ramah terhadap kaum penyandang difabilitas. Fasilitas yang tidak mendukung dapat diamati pada dimensi pintu yang tidak dapat mengakomodir penumpang berkursi roda, tidak terdapat kursi khusus penumpang dengan disabilitas, dan tinggi lantai bus yang tidak rata dengan platform di halte maupun terminal.

7) Tangible-5 (Kebersihan di Dalam Bus Kota)

Faktor yang menjadikan adanya kesenjangan pada indikator ini adalah tidak adanya upaya dari awak bus untuk senantiasa membersihkan bus ketika telah beroperasi. Tempat sampah juga tidak tersedia sehingga menyulitkan penumpang untuk membuang sampah. Kondisi yang demikian mendorong penumpang membuang sampah sembarangan dan membuat bus jadi terlihat kotor.

Secara umum, rata-rata nilai gap antara kinerja pelayanan dan harapan penumpang adalah sebesar (0.85). Nilai tersebut memberikan informasi bahwa pengelola perlu memberikan perhatian lebih sebagai upaya untuk meningkatkan kualitas pelayanan agar kesenjangan antara kinerja dengan harapan penumpang tidak terlalu jauh.

\section{Analisis Tingkat Kesesuaian}

Analisis tingkat kesesuaian dapat memberikan gambaran mengenai kepuasan penumpang terhadap pelayanan yang diberikan oleh operator bus kota. Hasil analisis tingkat kesesuaian antara kinerja pelayanan dan harapan penumpang dapat dilihat pada Tabel 5 .

Tabel 5. Tingkat kesesuaian (TKi)

\begin{tabular}{lcc}
\hline \multicolumn{1}{c}{ Indikator } & Tki & Kepuasan \\
\hline Kapasitas bus kota & 89,97 & Tinggi \\
Kerapian Awak Bus Kota & 87,27 & Tinggi \\
\hline Informasi Tarif Bus Kota & 82,48 & Tinggi \\
Ketetapan Tarif Bus Kota & 66,76 & Cukup \\
\hline Jaminan Keamanan & 78,60 & Cukup \\
Jaminan Keselamatan & 75,93 & Cukup \\
\hline Kesigapan Awak bus Kota & 90,40 & Tinggi \\
Ketersediaan Layanan Pengaduan & 67,08 & Cukup \\
\hline Tempat Duduk yang Nyaman & 82,43 & Tinggi \\
Ketersediaan Air Conditioner (AC) & 75,31 & Cukup \\
Interior Bus & 84,43 & Tinggi \\
Tersedianya Fasilitas Disabilitas & 57,14 & Cukup \\
Kebersihan di Dalam Bus Kota & 76,26 & Cukup \\
\hline \multicolumn{1}{c}{ Rata-rata } & 78,01 & Cukup \\
\hline
\end{tabular}

Merujuk pada Tabel 5, dapat disimpulkan bahwa penumpang cukup puas dengan pelayanan yang diberikan oleh operator bus kota. Hal ini 
mengindikasikan masih ada peluang perbaikan yang bisa diupayakan oleh operator sehingga diharapkan tingkat kepuasan penumpang dapat naik ke level sangat puas (kepuasan tinggi).

\section{Analisis Diagram IPA}

Perhitungan indeks kualitas pelayanan bus kota sebelumnya menunjukkan nilai rata-rata indeks kinerja dan harapan sebesar 3.06 (kinerja) dan 3.90 (harapan). Nilai indeks tersebut yang selanjutnya digunakan sebagai basis dalam analisis diagram IPA yang diolah menggunakan aplikasi SPSS. Diagram IPA pada dasarnya adalah diagram kartesius yang terdiri dari 4 (empat) kuadran yang nantinya berguna dalam menganalisis prioritas perbaikan pelayanan bus kota. Hasil analisis diagram IPA ditunjukkan dalam Gambar 1.

Pada kuadran A hanya terdapat 1 (satu) indikator yakni ketersediaan AC (tangible-2). Penumpang beranggapan bahwa pada kondisi suhu udara kota Surabaya yang relatif tinggi, AC adalah salah satu faktor yang mutlak harus ada, namun kinerja di lapangan sangat rendah sehingga operator harus menempatkan kedua indikator tersebut sebagai prioritas utama jika ingin meningkatkan kualitas pelayanan bus kota di Surabaya.

Kuadran B berisikan 7 (tujuh) indikator pelayanan yakni tempat duduk yang disediakan memberikan kenyamanan pada penumpang bus kota selama perjalanan (tangible-1), kebersihan didalam bus kota jaminan keamanan didalam bus selama perjalanan (assurance-2), informasi tarif bus kota sesuai dengan peraturan (responsiveness-1), kesigapan awak bus bus kota dalam melayani calon penumpang (emphaty-1), kapasitas bus kota yang memadai (realibility-1). Menurut persepsi penumpang, ketiga indikator ini sangat penting dan penumpang merasa sangat puas dengan kualitas ketiganya. Kedepan diharapkan operator dapat mempertahankan kualitas pelayanan pada ketiga indikator ini.

Terdapat 3 (tiga) indikator pelayanan pada kuadran $\mathrm{C}$ yakni ketersediaan fasilitas disabilitas (tangible4), ketersediaan layanan pengaduan (empathy-2) dan ketetapan tarif bus kota (responsiveness-2). Kuadran ini menunjukkan faktor yang dianggap tidak terlalu penting oleh penumpang sehingga operator tidak perlu memprioritaskan ketiga faktor ini dalam upaya perbaikan karena dalam persepsi penumpang, kuadran A perlu terlebih dahulu diperbaiki (diprioritaskan). Ada kemungkinan bahwa penumpang berasumsi bahwa ketiga indikator tersebut sukar untuk diperbaiki sehingga mereka tidak terlalu banyak berharap akan adanya perbaikan, namun operator juga tidak boleh mengabaikannya karena akan berimbas kepada kualitas pelayanan secara keseluruhan.

Kuadran D berisikan 2 (dua) indikator yakni interior bus (tangible-3) dan kerapian awak bus kota (reliability-2). Penumpang beranggapan bahwa kedua indikator tersebut sudah berjalan dengan baik

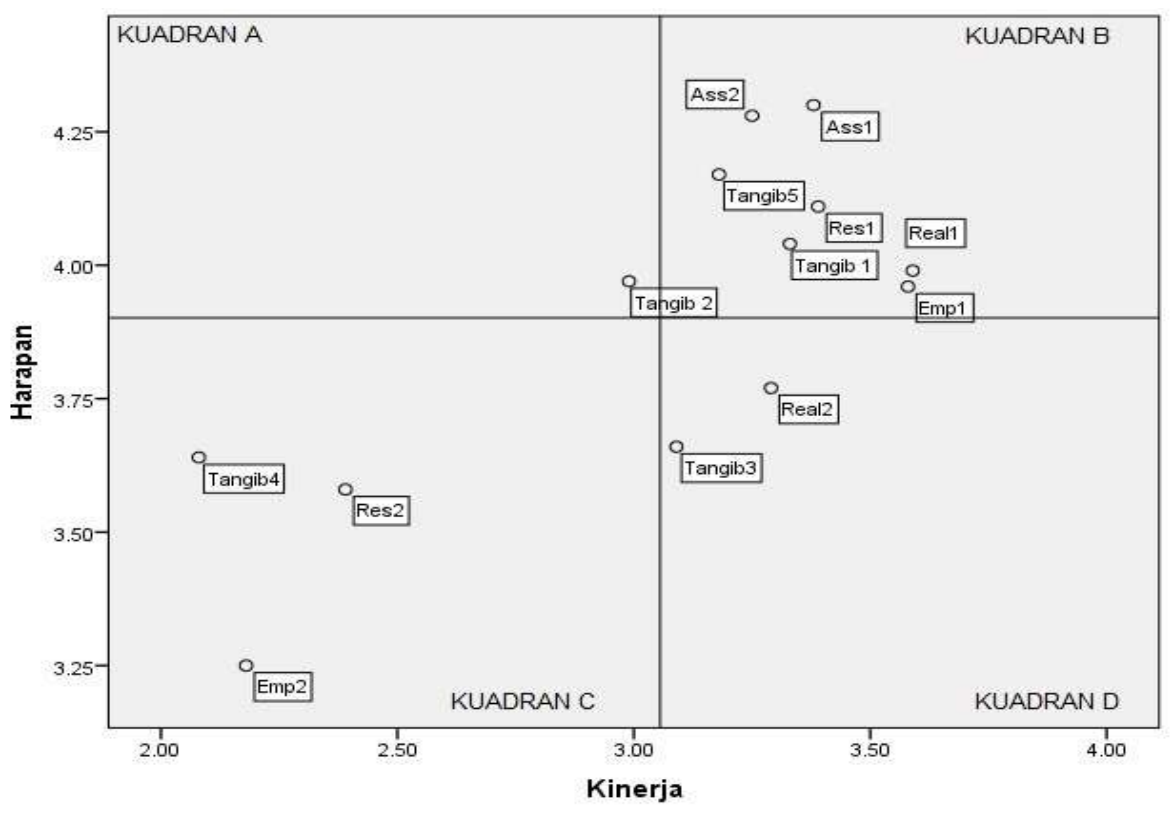

Gambar 1 Diagram IPA Kualitas Pelayanan Bus Kota Surabaya

(tangible-5), penumpang bus kota mendapat jaminan keselamatan didalam bus selama perjalanan (assurance-1), penumpang bus kota mendapat di lapangan, namun karena penumpang tidak melihatnya sebagai aspek yang utama dalam 
penilaian kualitas pelayanan bus kota, maka mereka juga tidak memberikan harapan yang terlalu tinggi.

\section{SIMPULAN}

Dari uraian sebelumnya, dapat disimpulkan beberapa hal sebagai berikut:

1. Nilai gap antara kinerja dan harapan penumpang bus kota di Surabaya menunjukkan nilai negatif yang artinya kinerja pelayanan bus kota belum mampu memenuhi harapan penumpang.

2. Analisis tingkat kesesuaian antara kinerja dan harapan menunjukkan bahwa penumpang berpendapat bahwa kualitas pelayanan bus kota di Surabaya sudah cukup memuaskan.

3. Prioritas utama perbaikan dalam rangka meningkatkan kualitas pelayanan seperti yang diharapkan oleh penumpang adalah dengan perbaikan fasilitas air conditioner (AC) di dalam bus kota.

\section{REFERENSI}

Aminah S, 2007. Transportasi Publik dan Aksesibilitas Masyarakat Perkotaan. Jurusan Ilmu Politik FISIP. Universitas Airlangga. Surabaya.

Basuki, Imam. 2008. Tanggapan Masyarakat terhadap pengoperasian Bis Perkotaan Patas Transjogja, Jurnal Transportasi, Vol. 8 Edisi khusus N0 1 Oktober 2008.

Beirao dan Cabral., 2007, Understanding Attitudes Towards Public Transport and Private Car: A Qualitative Study, Transport Policy, 14, 478489.

Budiono, Fahrizal Lukman, 2013, Persepsi dan harapan pengguna terhadap kualitaslayanan data pada smartphone di Jakarta. Buletin Pos dan Telekomunikasi, Vol.11 No.2 Juni 2013 : 93-108

Costa, M., Deme E., Jacquier, A., dan Michel, F., 1997, Multiple Tertiary Interactions Involving Domain Of Group Self Splicing Introns, J Mol Biol, in press.

F. Go and W. Zhang, 1997. Applying importanceperformance analysis to Beijing as an international meeting destination, Journal of Travel Research, vol. 35, no. 4, pp. 42-49.

J. E. Blose, W. B. Tankersley, and L. R. Flynn, 2005. Managing service quality using data envelopment analysis, Quality Management Journal, vol. 12, no. 2, pp. 7-24.

J. H. Carman, 1990. Consumer perceptions of service quality: An assessment of the SERVQUAL dimensions, Journal of Retailing, vol. 66, no. 1, pp. 33-55.
J. Martilla and J. James, 1997. Importanceperformance analysis, Journal of Marketing, vol. 41, no. 1, pp. 77-79, 1977.

M. Joseph and B. Joseph, 1997. Service quality in education: a student perspective, Journal Quality Assurance in Education, vol. 5, no. 1, pp. 15-21.

M. J. Enright and J. Newton, 2005. Determinants of tourism destination competitiveness in asia pacific:Comprehensiveness and Universality, Journal of Travel Research, vol. 43, no. 4, pp. 339-350

M. S. Wong, C. Fearon, and G. Philip, 2009. Evaluating E-government in Malaysia: An importance-performance grid analysis (IPA) of citizens and service providers, International Journal of Electronic Business, vol. 7, no. 2, pp. 105-129.

Parasuraman, A., Zeithaml, V.A. and Berry, L. 1985. A Conceptual Model of Service Quality and its Implications for Future Research. Journal of Marketing, 49, Fall, pp. 41-50.

Parasuraman, A., Zeithaml, V.A. and Berry, L. 1991. Refinement and Reassessment of The SERVQUAL Scale. Journal of Retailing. 67 (4) winter, pp. 420-50

R. D. Nale, D. A. Rauch, and S. A. Wathen, 2000. An exploratory look at the use of importance performance analysis as a curricular assessment tool in a school of business, Journal of Workplace Learning: Employee Counselling Today, vol. 12 , no. 4 , pp. 139145.

Schipper, L., Marie-Lilliu, C. and Gorham, R. 2000. Flexing the Link between Transport and Greenhouse Gas Emissions. A Path for the World Bank. International Energy Agency Paris, pp. 17-19.

Shen J, Li W. 2014. Discrete Hopfield neural networks (DHNN) for Evaluation Service Quality of Public Transit. International Journal of Multimedia and Ubiquitous Engineering Vol.9, No.2 p.331-340

Sugianto H, 2013. Evaluasi Kinerja Pelayanan Dinas Perhubungan Dalam Bidang Angkutan Umum Perkotaan, Journal of Public Administration Re- search (JOPAR), Vol 1, No1 2013 Hal 23

Sudibyo, T., Mahardi, P., Prasetyo, T., 2017, Perbandingan Penilaian Tingkat Pelayanan Jalan Menurut PM 96/2015 dan Km 14/2006, Prosiding Konferensi Nasional Teknik Sipil 11. Universitas Tarumanegara. Hal 183-188.

Supranto, J. Limakrisna, Nanden. 2007. Perilaku Konsumen dan Strategi Pemasaran. Mitra Wacana Media, Jakarta 
Tolba, M, K. and Saab, N. W. 2008. Arab Environment Future Challenges. Report of the Arab Forum for Environment and Development (AFED).

W. Fache, 2000. Methodologies for innovation and improvement of services in tourism, Managing Service Quality, vol.10, no. 6, pp. 356-366

Wong, M.S., Hideki, N. and Philip, G. 2011. "The Use of Importance-Performance Analysis (IPA) in Evaluating Japan's EGovernment Services," Journal of Theoretical and Applied Electronic Commerce Research, 6(2), 